\title{
Debating CRISPR/cas9 and Mitochondrial Donation: Continuity and Transition Performances at Scientific Conferences
}

\author{
NEIL STEPHENS \\ BRUNEL UNIVERSITY LONDON \\ REBECCA DIMOND \\ CARDIFF UNIVERSITY
}

\begin{abstract}
Conferences are important performative sites. Here we detail a UK science policy conference debating the novel biomedical techniques CRISPR/cas9 and mitochondrial donation. Both techniques have received significant attention from scientists and bioethicists about their clinical potential, social implications, and the prospects of genetic and germline modification. In many countries the policy debates on regulating both technologies is ongoing and operating in tandem. The UK, however, is operating in a distinct policy context in that mitochondrial donation was formally legalized under license in 2015, meaning the British CRISPR/cas9 debates occur in the light of a confirmed policy position on mitochondrial donation. Our analysis of the Progress Educational Trust 2015 annual conference 'From Three-Person IVF to Genome Editing' argues that this event conducted important staging work in articulating the relationship between these two technologies in the UK. These efforts constitute what we call a 'transition performance' that (i) enacted the successful resolution of the mitochondrial donation policy debate, (ii) performed the success of British biomedical politics, and (iii) opened the space for a public debate on CRISPR/cas9 in line with a specifically configured set of legitimacy practices. Subsequently the conference contrasts to many other conferences that fit what we term a 'continuity performance' that seek to assert consistency and progress through iteration. We close by articulating further applications and developments of these notions in Science and Technology Studies.
\end{abstract}

\section{Key Words}

scientific conferences; CRISPR; cas9; mitochondrial donation; mitochondria; gene editing; performative; performativity; embryo politics

'Neil Stephens, Email: neil.stephens@brunel.ac.uk 2 Rebecca Dimond, Email: dimondr1@cardiff.ac.uk

Copyright (c) 2017 (Neil Stephens and Rebecca Dimond). Licensed under the Creative Commons Attribution Noncommercial No Derivatives (by-nc-nd). Available at estsjournal.org. 


\section{Introduction}

The last two years have witnessed intense debates about the future potential and risks of controversial and novel technologies that could enable human genetic modification. Here we use the example of a conference about two such technologies-CRISPR/cas9 and mitochondrial donation--to articulate how conferences can be sites of transition performance that enact specific forms of biomedical political culture.

\section{Studying Conferences in STS}

Conferences are integral to scientific practice but remain under-analyzed within Science and Technology Studies (STS) (González-Santos and Dimond 2015). This is an oversight, as conferences are places of work akin to the laboratory or clinic: they enable members of a community to meet, to collaborate, and to discuss and present their work. Conferences are also symbolic of the ties that bind a community; they offer the opportunity for achievements to be celebrated, reputations to be established, and can simultaneously reflect, and shape, the nature of a field. Collins (2004) argues that conferences are sites in which "the community learns the etiquette of today's truth" ( $p$ 451). For Wainwright and Williams (2008) they are significant places of performance. We expand this emphasis by introducing two categories of conference performativities: "continuity performances" and "transition performances."

\section{Conference Performativities}

The STS notion of performativity is prefigured in many classics of philosophy and sociology (Butler 1993; Dewey 1946; Garfinkel 1967; Goffman 1959; Lyotard 1984; Peirce 1905; see Muniesa 2014 for a detailed account), and has found expression in works including Pickering (1995), Callon (1998), Brown and Michael (2003), and MacKenzie (2006). All focus on the capacity of discourses and actions to bring into being the identities, practices, and knowledge claims they operate to describe. Speaking of social science, Law and Urry suggest scientific "inquiry and its methods are productive: they (help to) make social realities and social worlds. They do not simply describe the world as it is, but also enact it" (Law and Urry 2004: 390-1, emphasis in original).

Conferences also enact. They make and remake worlds. Most scientific conferences are "continuity performances": a field, a research focus, or a set of methods is enacted as coherent and consistent. Importantly, this does not mean stasis: the community moves forward through articulating findings and innovations. Progress becomes a mechanism that allows change while retaining continuity with the past.

We contrast "continuity performances" with an example of "transition performance," in which a conference enacts progress through distinction, through rendering the modes of accountability to the recent past as different from those of the near future. We do so by focusing upon a UK science policy conference hosted by the Progress Educational Trust (PET) about two controversial biomedical technologies: CRISPR/cas9 and mitochondrial donation. We demonstrate how the PET conference worked, firstly, to enact the transition of mitochondrial 
donation from a status of open debate to one of successful closure, and, secondly, to introduce CRISPR/cas9 as a new debate in British biomedical political culture. In doing so, it staged a transition performance that rendered mitochondrial donation as evidence of that political culture's success. This occurred through excluding dissenting voices from the mitochondrial donation case, through asserting the strength of British biomedical political culture, and by staging and legitimizing multiple perspectives on CRISPR/cas9.

\section{Mitochondrial Donation and CRISPR/cas9}

In February 2015, the UK became the first (and still only) country in the world to legalize mitochondrial donation. Mitochondrial donation uses part of a donated egg in an In Vitro Fertilization (IVF) cycle to allow women with maternally inherited mitochondrial disease to have healthy, genetically related children. The techniques are controversial because genes from the mitochondrial donor can be passed on to future generations (known as "germline modification") (Baylis 2013; Bredenoord et al. 2011). The resulting child would have three genetic contributors (nuclear genes from the intending mother and father and mitochondrial genes from the egg donor) (Dimond 2015). The decision to change the law and allow the techniques followed several years of consultations, policy debates, and parliamentary votes, which culminated in a consensus that mitochondrial donation did not constitute genetic modification (which had been redefined as only involving the modification of nuclear genes) (DoH 2014). While the UK is the first to legalize the techniques, there are other countries in which the techniques are neither formally legal nor illegal. In 2003 a team in China lead by Prof. John Zhang attempted a similar procedure involving mitochondrial transfer in a human IVF procedure. Although three foetuses developed, it did not result in any live births (Cohen and Malter 2016; Zhang et al. 2016a). In September 2016 it was announced that Prof. Zhang's new USA based team had again conducted a mitochondrial donation IVF technique, this time performing the procedure in Mexico, and this time leading to the birth of a seemingly healthy baby boy (Hamzelou 2016; Zhang et al. 2016b). In contrast, the UK is yet to see a human pregnancy using a mitochondrial donation technique.

CRISPR/cas9 is a new type of gene-editing technique that allows the editing of hundreds of genes at once. It could be used to address complex disorders and character traits much more cheaply, quickly, and efficiently than any prior technique (Chan et al. 2015). Liang published the first work on CRISPR/cas9 gene-editing in abnormal human embryos as recently as 2015 (Liang et al. 2015), and although it has a short history, it has swiftly become a hot topic among biologists and bioethicists. Already we have calls for a moratorium (Hawkes 2015; Lanphier et al. 2015), a US government task force assessing biohacking risk (Knoepfler 2016), a patent dispute (Sheridan 2014), and a US Gene-editing Summit (Jasanoff et al. 2015). CRISPR/cas9 kits are now available online and the UK recently granted the world's first research license for human embryonic work, although this is predated by Liang's unlicensed work in China (Callaway 2016; Liang et al. 2015). Through CRISPR/ cas9 the technical capacity to genetically modify the human genome-and pass those modifications to future generations-could soon be a realistic possibility (Savulescu et al. 2015). 
In most countries debates about the safety and ethics of mitochondrial donation and CRISPR/cas9 are running concurrently. The UK is unique in that CRISPR/cas9 is being discussed after mitochondrial donation has been formally legalized.

\section{UK Biomedical Political Culture and the Progress Educational Trust}

The UK has developed a distinctive biomedical political culture over the last four decades featuring consultation processes, arms-length bodies, and a permissive but highly regulated and bureaucratized licensing approach to conducting ethically sensitive biomedical work. It is characterized by an emphasis on evidential culture (Salter et al. 2015), institutionalized ethics (Reubi 2013), and performances of transparency (Jasanoff 2005; Stephens et al. 2013). This model has been mobilized most effectively in a succession of embryo research programs, including IVF (Mulkay 1993), human embryonic stem cells (Mikami and Stephens 2016; Salter and Salter 2007), and more recently mitochondrial donation, that seek to enact the UK's global leadership in these areas.

The December 2015 Progress Educational Trust (PET) annual conference "From threeperson IVF to Genome editing: The Science and Ethics of Engineering the Embryo" is an example of transition performance, a site of political action, and an important location for STS-informed empirical analysis. PET is a small charitable organization that adopts a distinct but significant position within UK genetic and assisted conception policy debates. It performs a dual role as (typically pro-scientific) advocacy group and host of open debate. In its advocacy role, it submitted supportive responses to consultations on mitochondrial donation to the Human Fertilization and Embryology Authority (HFEA), the Nuffield Council on Bioethics, and the Department of Health. In its debate hosting role, it runs the web-based weekly newsletter "Bionews" and events including topic specific workshops and annual conferences. In previous years, the annual conference has focused on embryo research (2011), fertility treatment (2012), twins in genetics and fertility treatment (2013), the commercialization of life (2014) and most recently, the science and ethics of engineering the embryo. The 2015 event took place in the Department of Health conference center in London. This public event was attended by an audience of more than 300 , including scientists, ethicists, campaigners, journalists, government officials, social scientists and, no doubt, patients and interested citizens.

\section{From Three-person IVF to Genome Editing: Documenting Transition Performance}

In this section we demonstrate how the PET conference acted to record the technologies (in this case, mitochondrial donation and CRISPR/Cas9) as socially significant and worthy of public debate. It also worked as a transition performance to denote a shift for mitochondrial donation from debate to policy success, while staging the initial UK policy reflections and engagement encounter for CRISPR/cas9, and acting as a site of the nuanced positioning of the continuity and distinctness of the two technologies. It was also a restatement of a dominant sense of British 
biomedical political culture that has its roots in the IVF debates of the 1980s and continued through human embryonic stem cells, hybrid embryos, and now pre-implantation CRISPR/cas9.

Enacting the successful resolution of the mitochondrial donation policy debate

The morning featured a session on mitochondrial donation. The three speakers were: the scientist most visibly associated with the techniques, Prof. Doug Turnbull (whose talk was entitled "Why do we need mitochondrial donation?"); chair of the HFEA, Sally Cheshire ("Why the UK is the best place for mitochondrial donation"), and Viscount Matt Ridley (who described his and his colleagues' work to steer the Lord's debate towards a positive outcome). The presentations continued a narrative that featured heavily in the pre-vote debates about the suffering and tragedy of patient-families. This given, two notable differences between pre- and postparliamentary debate accounts were evident. Firstly, the PET conference accounts framed families with mitochondrial mutations as key beneficiaries of the collective policy success achieved through legalization, as opposed to their previous framing as potential victims of a vote against the techniques. Secondly, family representatives themselves were not present on stage at the PET event. This stands in contrast to many pre-vote public debates in which they were key speakers. The absence of patient-family voices suggests that on this occasion it was deemed unnecessary to deploy individualized and embodied suffering narratives as a tool for persuasion. Instead, this role was conferred to professionalized speakers and thus worked to enact their status as legitimate representatives of patient-family perspectives.

A second set of absent voices were those opposed to legalizing the mitochondrial donation techniques. PET have organized several panels discussing mitochondrial donation over the last two years, but this was the first that did not feature a speaker against the techniques on stage. In doing so, the conference effectively asserted the irrelevance of counter-mitochondrial donation perspectives to the British debate. Through this silencing of opposing voices, and conferring the capacity to speak on behalf of patient-families to biomedical, regulatory, and political professionals, the session was both celebrative and constitutive of the correctness of legalizing the techniques. It was the first component of the transition performance, rendering the recent past as accountable to the authority of the victors, and closing down debate on the topic.

\section{Performing the success of British biomedical politics}

Sally Cheshire's morning presentation, "Why the UK is the best place for mitochondrial donation," was followed by another invocation of Britishness in the afternoon, as the Chief Scientific Adviser to the UK Government--Prof. Sir Mark Walport-addressed "Why the UK should be leading the discussion on embryo engineering." He produced a classic mainstream narrative on the UK's successful biomedical political culture that featured the boundary work of a science/value distinction and a restatement of the HFEA's world-leading capacity for conducting excellent public consultation and its highly regulated but permissive licensing systems. This "UK as gold standard" trope is both accounted for, and enacted through, conferences of this form. They work to stage accountability through engagement and purposefulness through open 
debate. Importantly, through this move, mitochondrial donation is transitioned from being an open topic for discussion to being evidence of the UK system's success.

Transitioning to CRISPR/cas9 through performing legitimacy practices

The latter sessions of the conference focused on CRISPR/cas9. The discussion was implicitly staged as a milestone in opening UK policy debate on this issue, with the early talks explaining what CRISPR/cas9 is and what it could do. Regular features of biomedical political debate were quickly evident: metaphors presenting CRISPR/cas9 invoked bridges between genes, and the craft skill of the carpenter was likened to the scientist performing gene editing. Robin LovellBadge, scientist and prominent proponent of mitochondrial donation, articulated the potential uses of CRISPR/cas9, but argued that while he supports research development in the area, this did not equal endorsement for clinical use at this stage in the discussions.

The conference closed with a session on the ethics and law of engineering the embryo. Panelists Emily Jackson (lawyer), John Harris (bioethicist), Calum MacKellar (bioethicist), and Brendan McCarthy (The Church of England) articulated a range of opinions (contrasting starkly with the unified voices of the mitochondrial donation session). This given, only MacKellar spoke with sustained hostility towards CRISPR/cas9, and was singled out for thanks by the chair for representing these views amongst predominantly supportive speakers. This act of thanks is part of a nuanced etiquette of political legitimacy that works to show a sincere gratitude for an opinion that ultimately goes against the dominant trajectory articulated at the event. It is celebrative of the capacity to host diverse views, while knowing that ultimately this counter narrative is of a type that was unsuccessful in the previous mitochondrial donation debate, and may be so again from CRISPR/cas9. While this session was about CRISPR/cas9, all speakers drew upon the mitochondrial case as a resource in their accounts, stressing continuities and discontinuities between the two technologies. Key examples of this include speakers contesting which metaphors were appropriate to use for each technology, whether the timeframe for developing policy was too fast or too slow, and Britain's status as pioneer or maverick (with the latter exemplified in MacKellar's talk titled "Brave New British Babies," a reference to Aldous Huxley's (1932) dystopian novel on future IVF technologies).

\section{Transition and Continuity Performances and the Making of Biological Debate}

The PET conference enacted transition through staging open debate on CRISPR/cas9 (between invited speakers), while also consigning previous debate on mitochondrial donation to the past (through celebratory rhetoric and exclusion of contesting voices). It also conferred legitimacy to its own practices through a discourse of ongoing British success in this area. This British mainstream desire to be the first and the best to regulate mitochondrial donation imprints a prehistory, a narrative resource, and pre-drawn battle lines on embryo editing discussions. Across this history, by hosting multiple opinions on CRISPR/cas9 but only victorious voices on mitochondrial donation, the PET event rendered modes of accountability for the recent past as different to those of the near future. 
More broadly, we can understand the PET conference as one performative moment in a succession of enactments around UK biomedical politics. Others include the 2015 parliamentary votes that approved mitochondrial donation licensing, and the early 2016 HFEA decision to allow CRISPR/Cas9 in healthy human embryos, which again made the UK the first country to give regulatory approval for a controversial technology (Callaway 2016). These policy decisions fit more closely with classical notions of performativity in that they legally establish that which they state, and remake legal worlds (Austin 1962). This noted, the PET conference remains a significant site of the performance of the political process that supports these decisions, and requires STS attention.

\section{Analyzing Conference Performativities in Other Contexts}

The analysis here can be profitably extended by exploring other empirical contexts, documenting other modes of performativity, and further detailing their accomplishment. Conferences draw people together and (re)configure the aims and boundaries of their fields. They are constitutive of a field, not just reflective of it. Being attentive to how conferences perform this practical and symbolic work could be central to STS inquiry, highlighting ways in which different types of conference on different topics may enact different worlds in different ways. A patient or user conference can stage the collective effervescence of shared activism (Dimond et al. 2015); a scientific conference can make and remake disciplines; and a science policy conference like PET can enact the discourses of legitimacy of a national biomedical political culture. Analysts can ask what is performed, what is not, and how these performances are staged. In many conferences these are continuity performances that enact progress through stability. Identifying the mechanisms by which this occurs in different contexts is a rich area for STS exploration. Another area of expansion is adding further to the typology of continuity and transition performances through the empirical documentation of other types of conference enactment. By pursuing this important work the STS scholar is offering the richness and depth to conference studies that already furnishes laboratory and clinic ethnographies. In doing so, they further enrich STS.

\section{Acknowledgements}

The research reported in this article was funded by ESRC Future Research Leaders award (ref. ES / K00901X / 1) held by Dr. Dimond. We gratefully acknowledge that support.

\section{Author Biographies}

Dr. Neil Stephens is a sociologist based at Brunel University London. His current work is an ethnographic study of groups building robots for use in surgery. Previous research includes projects on human embryonic stem cell banking, cultured meat, and mitochondrial donation. 
Dr. Rebecca Dimond is a medical sociologist at Cardiff University, School of Social Sciences. Her research interests are patient experiences, clinical work, the classification of genetic syndromes and their consequences, and reproductive technologies.

\section{References}

Austin, J. L. 1962. How to Do Things with Words. Oxford: Clarendon Press.

Baylis, F. 2013. "The ethics of creating children with three genetic parents." Reproductive Biomedicine Online 26: 531-534.

Bredenoord, A.L., Dondorp, W., Pennings, G. and De Wert, G. 2011. "Ethics of modifying the mitochondrial genome." Journal of Medical Ethics 37(2): 97-100.

Brown, N. and Michael, M. 2003. "A sociology of expectations: retrospecting prospects and prospecting retrospects." Technology Analysis and Strategic Management 15 (1): 3-18.

Butler, J. 1993. Bodies that matter: on the discursive limits of 'sex'. London: Routledge.

Callaway, E. 2016. "UK scientists gain licence to edit genes in human embryos." Nature, February 1. Accessed 31 October 2016. http:/ / www.nature.com/news/uk-scientists-gain-licenceto-edit-genes-in-human-embryos-1.19270

Callon, M. 1998. "Introduction: The Embeddedness of Economic Markets in Economics." In The Laws of the Markets, edited by M. Callon, 1-57. Oxford: Blackwell.

Chan, S., Donovan, P. J., Douglas, T., Gyngell, C., Harris, J., Lovell-Badge, R., et al. \& On Behalf of the Hinxton Group. 2015. "Genome Editing Technologies and Human Germline Genetic Modification: The Hinxton Group Consensus Statement." The American Journal of Bioethics 15(12): 42-47.

Cohen, J. and Malter, H. 2016. The first clinical nuclear transplantation in China: new information about a case reported to ASRM in 2003. Reproductive BioMedicine Online 33(4): 433-435.

Collins H.M. 2004. Gravity's Shadow: The Search for Gravitational Waves. Chicago: University of Chicago Press.

Department of Health (2014) "Mitochondrial Donation: Government response to the consultation on draft regulations to permit the use of new treatment techniques to prevent the transmission of a serious mitochondrial disease from mother to child." 27 February. Accessed 31 October 2016. https://www.gov.uk/government/consultations/seriousmitochondrial-disease-new-techniques-to-prevent-transmission.

Dewey, J. 1946. "Peirce's theory of linguistic signs, though, and meaning." The Journal of Philosophy 43(4): 85-95.

Dimond, R. 2015. "Techniques of donation: 'three parents', anonymity and disclosure." Journal of Medical Law and Ethics 3(3): 165-173.

Dimond, R., Bartlett, A. and Lewis, J. T. 2015. "What binds biosociality? The collective effervescence of the parent conference." Social Science \& Medicine 126: 1-8.

Garfinkel, H. 1967. Studies in Ethnomethodology. Englewood Cliffs New Jersey: Prentice-Hall.

Goffman, E. 1959. The Presentation of Self in Everyday Life. Garden City New York: Anchor books. 
González-Santos, S. and Dimond, R. 2015. "Medical and scientific conferences as sites of sociological interest: A review of the field." Sociology Compass 9(3): 235-245.

Hamzelou, J. 2016. "Exclusive: World's first baby born with new "3 parent" technique." New Scientist, 27 September 2016. Accessed 31 October 2016. https: / / www.newscientist.com / article / 2107219-exclusive-worlds-first-baby-born-withnew-3-parent-technique.

Hawkes, N. 2015. “UK scientists reject call for moratorium on gene editing." BMJ 350: h2601.

Huxley, A. 1932. Brave New World. New York: Harper \& Brothers.

Jasanoff, S. 2005. Designs on Nature. Princeton, NJ: Princeton University Press.

Jasanoff, S., Hurlbut, B. and Saha, K. 2015. "CRISPR democracy: Gene editing and the need for inclusive deliberation. Issues in Science and Technology." Issues in Science and Technology 321: 25-32. Available at: http:/ / issues. org/32-1/ crispr-democracy-gene-editing-and-theneed-forinclusive-deliberation/

Knoepfler, P. 2016. “Exploring heritable genetic modification: the promise and perils of altering future humans." The Center for Genetics and Society, Online Conversation, 26 January 2016. Accessed 31 October 2016. http:/ / www.geneticsandsociety.org/article.php?id=9096.

Lanphier, E., Urnov, F., Haecker, S.E., Werner, M. and Smolenski, J. 2015. “Don't edit the human germ line." Nature 519(7544): 410-411.

Law, J. and Urry, J. 2004. "Enacting the social." Economy and Society 33(3): 390-410.

Liang, P., Xu, Y., Zhang, X., Ding, C., Huang, R., Zhang, Z., Lv, J., Xie, X., Chen, Y., Li, Y. and Sun Y. 2015. "CRISPR/Cas9-mediated gene editing in human tripronuclear zygotes." Protein E Cell 6 (5): 363-72. http:/ / dx.doi.org/10.1007/s13238-015-0153-5

Lyotard, J.-F. 1984. The Postmodern Condition: a Report on Knowledge. Minneapolis (Minnesota): University of Minnesota Press.

MacKenzie, D. 2006. An Engine, Not a Camera: How Financial Markets Shape Markets. Cambridge (Massachusetts): The MIT Press.

Mikami, K. and Stephens, N. 2016. "Local biologicals and the politics of standardisation: making ethical pluripotent stem cells in the UK and Japan." Biosocieties 11(2): 220-239.

Mulkay, M. 1993. "Rhetorics of hope and fear in the great embryo debate." Social Studies of Science 23(4): 721-742.

Muniesa, F. 2014. The Provoked Economy: Economic Reality and the Performative Turn. Abingdon: Routledge.

Peirce, C.S. 1905. “What pragmatism is." The Monist 15(2): 161-81.

Pickering, A. 1995. The Mangle of Practice: Time, Agency and Science. Chicago: The University of Chicago Press.

Reubi, D. 2013. "Re-moralising medicine: The bioethical thought collective and the regulation of the body in British medical research." Social Theory \& Health 11(2): 215-235.

Salter, B. and Salter, C. 2007. "Bioethics and the Global Moral Economy: The Cultural Politics of Human Embryonic Stem Cell Science." Science Technology and Human Values 32(5): 554581. 
Salter, B., Zhou, Y. and Datta, S. 2015. "Hegemony in the marketplace of biomedical innovation: Consumer demand and stem cell science." Social Science \& Medicine 131: 156-163.

Savulescu, J., Pugh, J., Douglas, T. and Gyngell, C. 2015. “The moral imperative to continue gene editing research on human embryos." Protein $\mathcal{E}$ Cell 6(7): 476.

Sheridan, C. 2014. "First CRISPR-Cas patent opens race to stake out intellectual property." Nature Biotechnology 32(7): 599-601.

Stephens, N., Atkinson, P., and Glasner, P. 2013. “Institutional Imaginaries of Publics in Stem Cell Banking: The Cases of the UK and Spain." Science as Culture 22(4): 497-515.

Wainwright S.P. and Williams C. 2008. "Spaces of Speech and Places of Performance: An Outline of a Geography of Science Approach to Embryonic Stem Cell Research and Diabetes." New Genetics and Society 27(2): 161-173.

Zhang, J., Zhuang, G., Zeng, Y., Grifo, J., Acosta, C., Shu, Y. and Liu, H. 2016a. "Pregnancy derived from human zygote pronuclear transfer in a patient who had arrested embryos after IVF." Reproductive BioMedicine Online 33(4): 529 - 533.

Zhang, J., Liu, H., Luo, S., Chavez-Badiola, A., Liu, Z., Yang, M., Munne, S., Konstantinidis, M., Wells, D. and Huang, T. 2016b. "First live birth using human oocytes reconstituted by spindle nuclear transfer for mitochondrial DNA mutation causing Leigh syndrome." Fertility and Sterility 106(3): e375 - e376. 